\title{
Morphology and Melt Rheology of Nylon 11/Clay Nanocomposites
}

\author{
Xiaofeng He, ${ }^{1}$ Jun Yang, ${ }^{2}$ Lianchao Zhu, ${ }^{2}$ Biao Wang, ${ }^{1}$ Guangping Sun, ${ }^{1}$ Pengfei Lv, ${ }^{3}$ \\ In Yee Phang, Tianxi Liu ${ }^{5}$ \\ ${ }^{1}$ College of Materials Science and Engineering, Jilin University, Changchun 130025, People's Republic of China \\ ${ }^{2}$ Department of Polymeric Materials and Engineering, State Key Laboratory of Polymer Physics and Chemistry, \\ Changchun Institute of Applied Chemistry, Chinese Academy of Sciences, Changchun 130022, People's Republic of \\ China \\ ${ }^{3}$ Facility Division, Pingdingshan Institute of Technology, Pingdingshan 467001, People's Republic of China \\ ${ }^{4}$ Department of Materials Science and Technology of Polymers, Faculty of Science and Technology, University of \\ Twente, AE ENSCHEDE, The Netherlands \\ ${ }^{5}$ Key Laboratory of Molecular Engineering of Polymers of Chinese Ministry of Education, Department of \\ Macromolecular Science, Fudan University, Shanghai 200433, People's Republic of China
}

Received 13 April 2005; accepted 10 November 2005

DOI 10.1002/app.24281

Published online in Wiley InterScience (www.interscience.wiley.com).

\begin{abstract}
Nylon 11 (PA11)/clay nanocomposites have been prepared by melt-blending, followed by melt-extrusion through a capillary. Transmission electron microscopy shows that the exfoliated clay morphology is dominant for low nanofiller content, while the intercalated one is prevailing for high filler loading. Melt rheological properties of PA11 nanocomposites have been studied in both linear and nonlinear viscoelastic response regions. In the linear regime, the nanocomposites exhibit much higher storage modulus $\left(G^{\prime}\right)$ and loss modulus $\left(G^{\prime \prime}\right)$ values than neat PA11. The values of $G^{\prime}$ and $G^{\prime \prime}$ increase steadily with clay loading at low concentrations, while the $G^{\prime}$ and $G^{\prime \prime}$ for the sample with $5 \mathrm{wt} \%$ clay show an inverse dependence and lie between the modulus values of the samples with 1 and 2 wt \% of clay.
\end{abstract}

This is attributed to the alignment/orientation of nanoclay platelets in the intercalated nanocomposite induced by capillary extrusion. In the nonlinear regime, the nanocomposites show increased shear viscosities when compared with the neat resin. The dependence of the shear viscosity on clay loading has analogous trend to that of $G^{\prime}$ and $G^{\prime \prime}$. Finally, a comparison has been made between the complex and steady viscosities to verify the applicability of the empirical CoxMerz rule. (C) 2006 Wiley Periodicals, Inc. J Appl Polym Sci 102: 542-549, 2006

Key words: nylon 11; nanocomposites; morphology; rheology

\section{INTRODUCTION}

Polymer/clay nanocomposites have aroused considerable concerns from both industrial and academic circles in recent years. The layer-structured clay is naturally hydrophilic. They become organophilic by modifying the silicate surfaces with organic cations by ion exchange reaction. The organoclay thus obtained has been incorporated into a variety of polymeric matrices successfully by in situ polymerization, melt or solution blending. ${ }^{1-16}$ The resulting nanocomposites show significantly enhanced mechanical properties, dimensional stability, permeability, and fire-resistance relative to the counterpart polymers. Therefore, the polymer/clay nanocomposites have found wider applications in automotive industry, packaging, aero-

\footnotetext{
Dedicated to Dr. Jun Yang (CIAC), who passed away on August 22, 2004.

Correspondence to: T. Liu (txliu@fudan.edu.cn).
}

Journal of Applied Polymer Science, Vol. 102, 542-549 (2006) (c) 2006 Wiley Periodicals, Inc. space, and some commercial products are now available in the market, such as nylon 6 and polypropylene based nanomaterials. ${ }^{17}$ Furthermore, the inserted macromolecules in the nano-sized clay galleries provide ideal models for examining the polymer conformation in a confined environment.

Generally speaking, there are two types of nanostructures in polymer/clay nanocomposites: intercalated and exfoliated. X-ray diffraction (XRD) technique is frequently employed to characterize the clay morphology in the resulting nanocomposites. The intercalation refers to that the polymers are inserted between the clay layers, making the clay stacks swollen up. The intercalation is evidenced by XRD as the characteristic reflection peak of natural clay shifts to lower scattering angles. The exfoliation refers to the individual clay layers are delaminated and dispersed separately throughout the polymeric matrix. Under this circumstance, the absence of characteristic reflection peaks of clay on the XRD pattern is an indicative of formation of the exfoliated structure. To further differentiate between the intercalated and exfoliated 
nanostructures, transmission electron microscopy (TEM) technique is usually another good tool to be performed by observing the microtomed slices of the nanocomposite samples.

Since large surface area, high aspect ratio, and good interfacial interaction are regarded as the essentials to produce nanocomposite materials with outstanding properties, the exfoliated structures are most preferred. For the preparation of nylon-based nanocomposites by melt-blending, the processing conditions, melt rheology, and the methods of surface modification of the clay should be taken into account. ${ }^{18}$ Thus, the melt rheology characterization (including steady, oscillation, and transient tests) for the nanocomposites is of importance. On the one hand, the rheological properties are the concerns of the technicians to obtain plastic products with better quality during injection molding, spinning, blowing, and other polymer processing processes. On the other hand, the morphologies of the layered clay particles in the polymer melt are changing under shearing conditions. The transient evolutions, such as agglomeration, breaking or orientation of clay particles, and interaction between the matrix and the clay platelets, could be recorded by combining versatile rheological testing modes.

The pioneering work on nylon 6/clay nanocomposites was first developed by Toyota research group. ${ }^{14-16}$ Extensive investigations on preparation, structural, morphological characterization as well as physical properties of polymer/clay nanocomposites have since been followed, especially for nylon 6-based clay systems. ${ }^{19}$ However, less attention has been paid to other nylon matrices, such as nylon 11 and nylon 12 . It is well known that nylon 11 is an important commercial polyamide with excellent piezoelectricity and mechanical properties and used in a large range of industrial fields from automotive to offshore applications. In our previous report, the preparation and characterization of the nylon 11 (PA11)/clay nanocomposites have been investigated. ${ }^{20}$ In the present study, the rheological properties in both linear and nonlinear viscoelasticity regions are investigated for PA11/clay nanocomposites with 1, 2, and $5 \mathrm{wt} \%$ clay loadings. The main aim of this study is to investigate the effect of clay addition on the rheological properties of PA11 matrix, as well as the relationship between clay morphology and melt rheology of the nanocomposites. Also, an attempt is made to verify the applicability of the Cox-Merz rule for PA11 and its clay nanocomposites.

\section{EXPERIMENTAL}

\section{Materials and sample preparation}

PA11/clay nanocomposites were prepared by melt blending on a Brabender twin-screw extruder at $220^{\circ} \mathrm{C}$ with a screw speed of $80 \mathrm{rpm}$, the extrudates were then cut into pellets. Both PA11 and organically modified clay (organoclay) are commercial products. ${ }^{19}$ Neat PA11 was treated with the same procedures as the nanocomposites for comparison. The pellets have a diameter of about $1 \mathrm{~mm}$ and dried for $48 \mathrm{~h}$ at $100^{\circ} \mathrm{C}$ before using. Film samples with thickness of about 1 $\mathrm{mm}$ for rheology tests were prepared by compression molding on a press at $220^{\circ} \mathrm{C}$ and 150 bar, followed by cooling to room temperature in air under pressure.

\section{Clay morphology by TEM}

The morphology of PA11/clay nanocomposites was investigated using a Philips CM300-FEG TEM at an accelerating voltage of $200 \mathrm{kV}$. Thin sections with thickness of $80 \mathrm{~nm}$ were cut from the extrudates by using a Leica ultramicrotome (equipped with a diamond knife under cryogenic condition) for subsequent TEM observations.

\section{Rheology tests}

Dynamic and steady-state shearing measurements were performed with a Paar Physica rotational rheometer (MCR 300) using $25 \mathrm{~mm}$ parallel geometry with a fixed plate-plate gap of $0.8 \mathrm{~mm}$. Amplitude sweeps were performed in advance to ensure that the dynamic tests were in the linear viscoelasticity region; and the strain values between 5 and $10 \%$ were consequently chosen. Frequency range from 0.1 to $100 \mathrm{rad} / \mathrm{s}$ and shear rate range from 0.01 to $100 \mathrm{~s}^{-1}$ were used for dynamic and steady-state tests, respectively. All the tests were run under nitrogen atmosphere.

\section{RESULTS AND DISCUSSION}

\section{Clay morphology}

Clay morphology throughout the polymeric matrix is illustrated by TEM observations (Fig. 1) for PA11 nanocomposites containing 2 and 5 wt \% clay. It can be seen that the nanoclay platelets with thickness of about $1 \mathrm{~nm}$ are homogeneously dispersed in the matrix. Clearly, at lower clay loading (e.g., 2 wt \%), a disordered and exfoliated clay nanostructure is observed [Fig. 1(A)], whereas at higher clay concentration (e.g., $5 \mathrm{wt} \%$ ), a typical ordered intercalated nanoclay morphology is seen [Fig. 1(B)]. Close inspection of the intercalated clay reveals that the layered structure of nanoclay maintain with spacing of about $5 \mathrm{~nm}$ or more, as shown in Figure 1(C), although some clay platelets are delaminated throughout the matrix. It is known that in practice it is difficult to get fully exfoliated polymer nanocomposites at higher clay loadings, especially via melt intercalation approach. The relative fraction of intercalation/exfoliation usually 

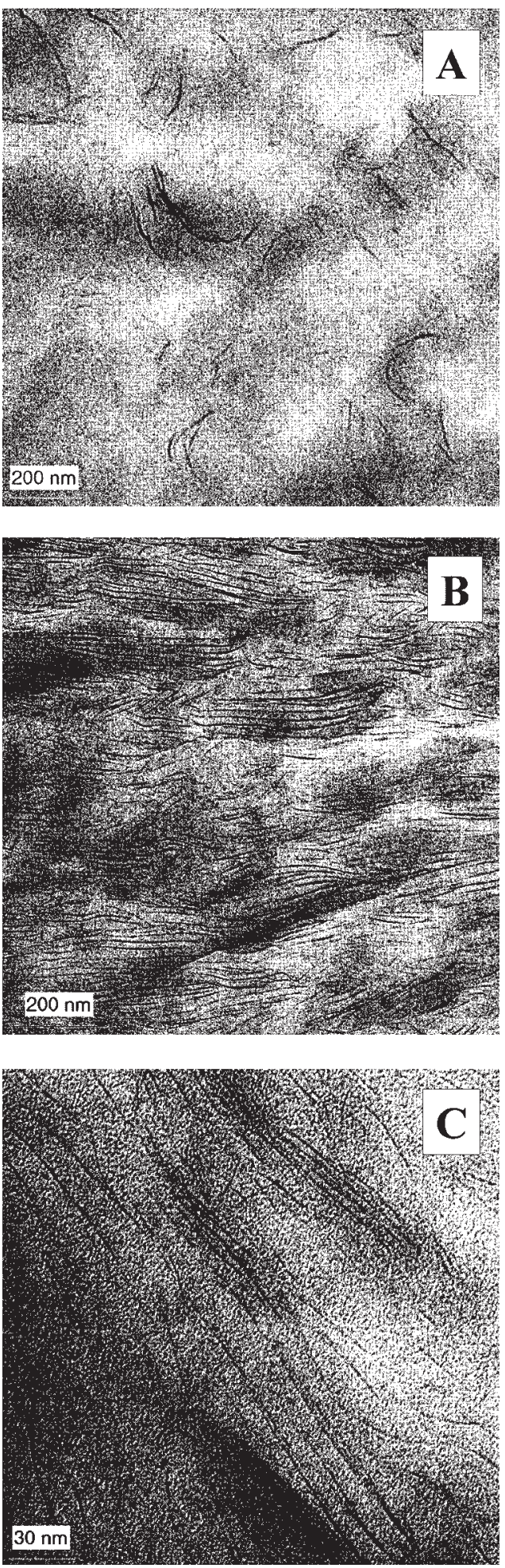

Figure 1 TEM images showing clay morphology for PA11 nanocomposite samples with 2 wt \% (A) and $5 \mathrm{wt} \%$ (B) clay, respectively. (C) TEM image of (B) at higher magnification.

increases with increasing the clay concentration. Thus, the coexistence of exfoliated and intercalated nanostructures is frequently observed in a number of thermoplastic and thermoset polymer/clay nanosys- tems. ${ }^{19}$ And, the complexity of clay morphologies within the polymer matrix may be reflected by the changes in the rheological behavior of the nanomaterials obtained.

\section{Linear viscoelasticity}

Usually, nylons have narrow temperature ranges for melt viscoelastic tests so that adequate data cannot be obtained for generating master curves. PA11 begins to melt at about $175^{\circ} \mathrm{C}$ and ends the melting event at about $200^{\circ} \mathrm{C}$, as reported on the differential scanning calorimetry curves. ${ }^{21}$ The equilibrium melting point $\left(T_{m}\right)$ of PA11 was estimated to be about $203^{\circ} \mathrm{C}^{22}$ Hence, melt rheology measurements for PA11 and its clay nanocomposite samples were carried out in this study at the temperatures above $203^{\circ} \mathrm{C}$. Figure 2 gives the time sweeps under oscillation shearing for neat PA11 at different temperatures. It can be seen that storage modulus $\left(G^{\prime}\right)$ and the loss modulus $\left(G^{\prime \prime}\right)$ almost remain constant over the time at $210^{\circ} \mathrm{C}$ for half an hour, whereas $G^{\prime}$ and $G^{\prime \prime}$ steadily increase as a function of time at $215^{\circ} \mathrm{C}$, and $G^{\prime}$ increases more rapidly than $G^{\prime \prime}$, indicating that stable viscoelastic responses can be obtained at $210^{\circ} \mathrm{C}$ for PA11 systems. Therefore, all the rheology tests in present study were performed at this temperature.

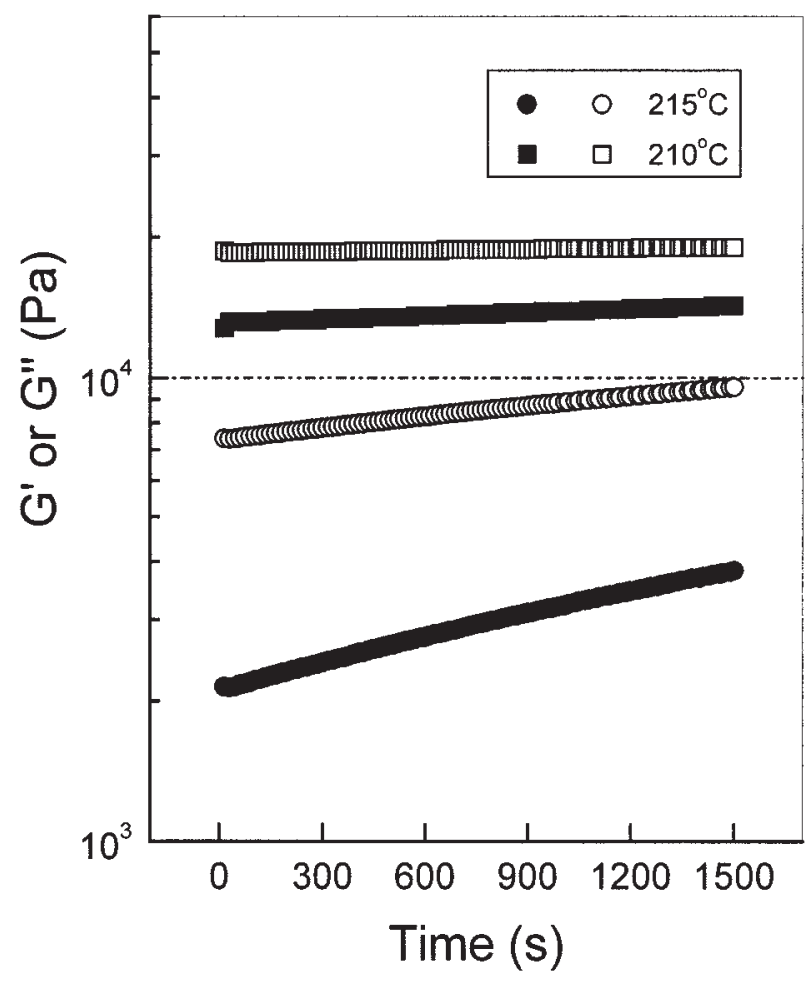

Figure 2 Variation of storage modulus ( $G^{\prime}$, solid symbols) and loss modulus ( $G^{\prime \prime}$, open symbols) during the oscillation time sweeps for neat PA11 at an angular frequency of 1.0 $\mathrm{rad} / \mathrm{s}$ at different temperatures. 


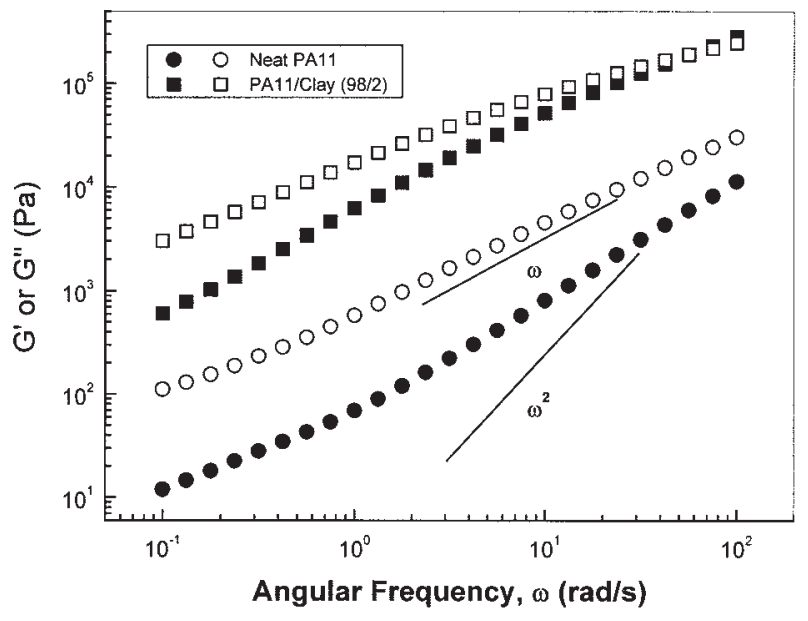

Figure 3 Storage modulus $\left(G^{\prime}\right.$, solid symbols) and loss modulus ( $G^{\prime \prime}$, open symbols) versus frequency for neat PA11 and the nanocomposite with $2 \mathrm{wt} \%$ clay loading, at a strain amplitude of $5 \%$ and $210^{\circ} \mathrm{C}$.

The linear viscoelastic response as measured by the storage and loss moduli ( $G^{\prime}$ and $\left.G^{\prime \prime}\right)$ for neat PA11 and the nanocomposite with $2 \mathrm{wt} \%$ clay is shown in Figure 3. It is known that $G^{\prime}$ and $G^{\prime \prime}$ represent the elastic and viscous responses of the studied system, respectively. For neat PA11, the frequency dependence of $G^{\prime}$ and $G^{\prime \prime}$ shows that the $G^{\prime \prime}$ value is considerably greater than the $G^{\prime}$ value and no intersection of the two moduli is found, suggesting that PA11 exhibits viscoelastic liquid characteristics under shear. Similar results were observed for the nanocomposites with 1 and $5 \mathrm{wt} \%$ clay (not shown here for abbreviation). However, for the nanocomposite with $2 \mathrm{wt} \%$ clay, an intersection of the $G^{\prime}$ and $G^{\prime \prime}$ curves at higher frequencies is observed as shown in Figure 3. The intersection is usually associated with the transition from the plateau zone to terminal region of the polymers, i.e., changing the rheological behavior from a viscoelastic solid (where $G^{\prime}>G^{\prime \prime}$ ) to a viscoelastic liquid (where $G^{\prime}<G^{\prime \prime}$ ). ${ }^{23}$ This indicates that PA11 nanocomposite becomes more elastic for the case of 2 wt \% clay loading. However, the intersection is not observed for the nanocomposite with higher clay content (e.g., 5 wt \%), which may be attributed to the difference in clay morphologies at low and high clay loading levels, as discussed later.

According to linear viscoelastic theory, in the terminal region (where frequency approaches 0 ), $G^{\prime}$ and $G^{\prime \prime}$ are proportional to $\omega 2$ and $\omega 1$, respectively. In other words, the slopes of $\log \left(G^{\prime}\right)$ versus $\log (\omega)$ and $\log \left(G^{\prime \prime}\right)$ versus $\log (\omega)$ at low frequencies (i.e., terminal zone) should be equal to 2 and 1, respectively. However, it was found that neat PA11 exhibits deviation from the estimated terminal behavior, especially for the case of the $G^{\prime}$, as shown in Figure 3. Similar observation was reported for polystyrene. ${ }^{23}$ This is probably due to the wide molecular weight distribution of PA11 used. For a wide molecular weight distribution, as in most commercial polymers, the terminal zone is broadened enormously and extended to much longer time or lower frequencies than that for the polymers with narrow molecular weight distribution.

The dependence of clay loading on the storage modulus is shown in Figure 4. The loss modulus shows similar trend and is not shown here for abbreviation. It can be seen that PA11/clay nanocomposites display much higher $G^{\prime}$ values than neat PA11. The value of $G^{\prime}$ increases with increasing clay loadings for the samples with 1 and 2 wt \% clay, while the sample with 5 wt \% clay has relatively lower $G^{\prime}$ values when compared with the one with 2 wt \%. This may be related to the dispersion state of clay in the matrix. For the nanocomposites with low clay loading (e.g., $\leq 2 \mathrm{wt} \%$ ), the exfoliated clay morphology is dominant [see Fig. $1(\mathrm{~A})]$, and the nanostructured platelets are uniformly dispersed throughout the matrix. For the nanocomposites with high clay content (e.g., $\geq 5 \mathrm{wt} \%$ ), stacked clay platelets are visible by TEM observations [see Figs. 1(B) and 1(C)]. Higher modulus shown in Figure 4 (and higher viscosity shown in Fig. 6) for the $2 \mathrm{wt} \%$ intercalation-dominated nanocomposite (than that of the 5 wt \% exfoliation-dominated sample) probably arises from the confinement of polymer chains within the intercalated clay layers. ${ }^{24}$ It has been reported that the viscosity of confined polymer melts is greater than that of bulk chains. ${ }^{25,26}$ The large viscosity of confined melts is believed to arise from an "immobilized hydrodynamic layer" near the wall having a thickness of the order of radius of gyration of the polymer chains. ${ }^{25}$

At relatively high clay concentrations (such as $5 \mathrm{wt}$ $\%)$, however, the distance between the clay layers is comparable to or even smaller than the size of a single

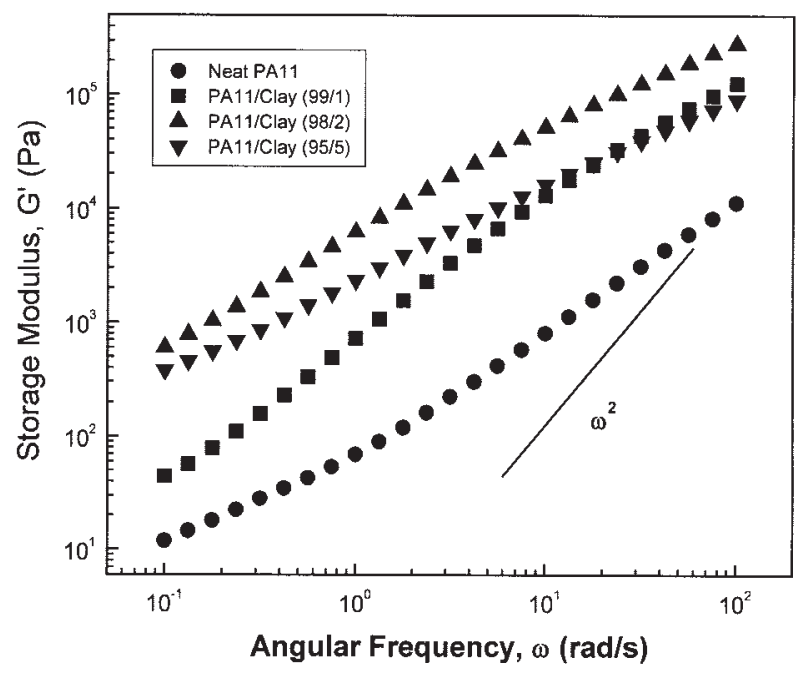

Figure 4 Storage modulus versus frequency for neat PA11 and its clay nanocomposites at strain amplitude of $5 \%$ at $210^{\circ} \mathrm{C}$. 
layer of clay. This means that the clay layers would strongly interact with each other. Under such circumstance, even if the nanocomposite is fully exfoliated, the rheology behavior may not be the same as the one at lower clay concentrations. It can thus be expected that the sample with $5 \mathrm{wt} \%$ clay loading would have a higher modulus than the one with $2 \mathrm{wt} \%$ clay, only if the clay platelets are in the state of exfoliation for both cases. Therefore, the intercalation morphology weakens the reinforcing effect of clay in the polymers. This is also the reason why people pursue exfoliated nanocomposites other than intercalated ones.

The minor cause for depressing the modules in the nanocomposite with $5 \mathrm{wt} \%$ clay could be due to the alignment of the stacked clay domains along the extrusion direction. The ordering of the clay platelets in the intercalated nanocomposite (with 5 wt \% clay) would have much influence on the viscoelastic response of the material, as observed for polycaprolactone/clay nanocomposites, ${ }^{27}$ where both storage and loss moduli for the aligned samples were considerably lower than those for the initially unaligned samples. The authors emphasized the influence of some shear and elongation history during extrusion on the alignment of layered silicates in the compression-molded samples.

Furthermore, the apparent plateau at low frequencies in $G^{\prime}$ and $G^{\prime \prime}$ curves, which is frequently observed for other intercalated polymer/clay nanocomposites, ${ }^{28,29}$ is absent here for PA11/clay systems. The results are in agreement with those for nylon 6/clay hybrids. ${ }^{27}$ The frequency-independent behaviors are deemed to associate with the network structures formed in the nanocomposites. As shown in Figure 5, there are possibly two morphologies of clay dispersion in the nanocomposites: one is that each clay particle (containing stacked platelets) is dispersed homogeneously in the matrix [Fig. 5(A)]; and the other is thermodynamically unstable gelation and network formed by the aggregated clay particles [Fig. 5(B)]. For PP/clay hybrids, ${ }^{28}$ it was found that the presence of plateau zone is closely related to the formation of a weakly agglomerated network structure of multi-platelet particulate domains. Thus, the absence of plateau zone for PA11 nanocomposite with 5 wt \% clay may imply a weak interaction among the clay particles, thus leading to a homogeneously structured material in PA11/clay system. Combined with the TEM images, the linear rheological measurements are useful for providing some valuable information in morphological difference between exfoliated and intercalated structures, for instance, in differentiating the intercalated nanocomposites with agglomerated clay network from the ones with homogeneous clay distribution.

\section{Nonlinear rheological properties}

In comparison with the linear viscoelastic response at small strains in frequency sweeps, the steady shear
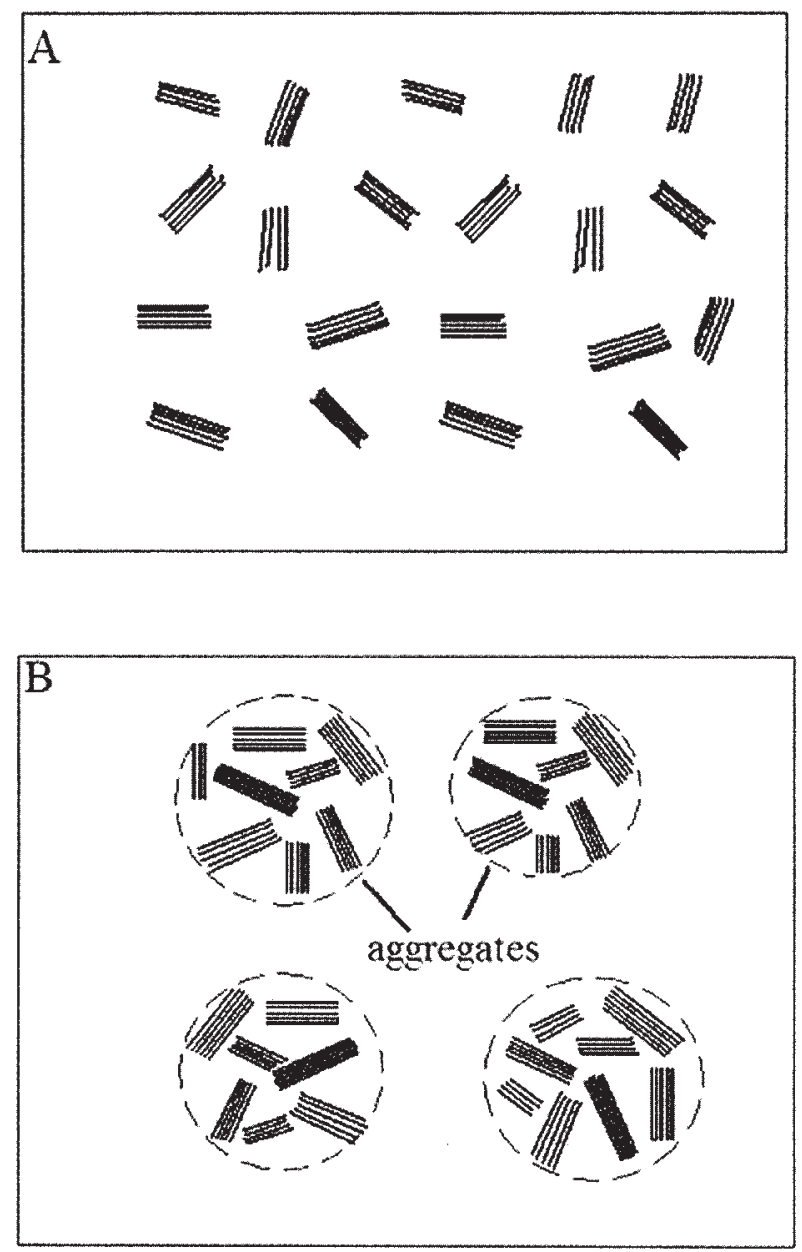

Figure 5 Schematic of two possible morphologies of stacked clay particles in the intercalated nanocomposites: (A) homogeneous dispersion without interaction between the clay particles; (B) aggregates of clay stacks (leading to uneven distribution).

response of polymer/clay nanocomposites usually provides useful information on processability of the material. The steady shear viscosity as a function of shear rate for PA11 and its nanocomposites is shown in Figure 6 as a function of clay loading. The viscosities of the nanocomposites are much higher than that of neat PA11. Each flow curve displays a similar profile with shear rate independent viscosity plateau at lower shear rates and shear thinning at higher shear rates. For the exfoliated hybrids (with 1 and 2 wt \% clay), the viscosities increase with increasing the clay loading. For the intercalated hybrid (with 5 wt \% clay), the flow curve is located between the two exfoliated samples and intersects with $1 \mathrm{wt} \%$ sample at higher shear rates. This phenomenon is quite similar to the case of the storage modulus, as discussed earlier in Figure 4.

To investigate the dependence of the viscosity $(\eta)$ on the shear rate $(\dot{\gamma})$, Carreau model ${ }^{30}$ was employed to fit the non-Newtonian viscosity curve for neat PA11 


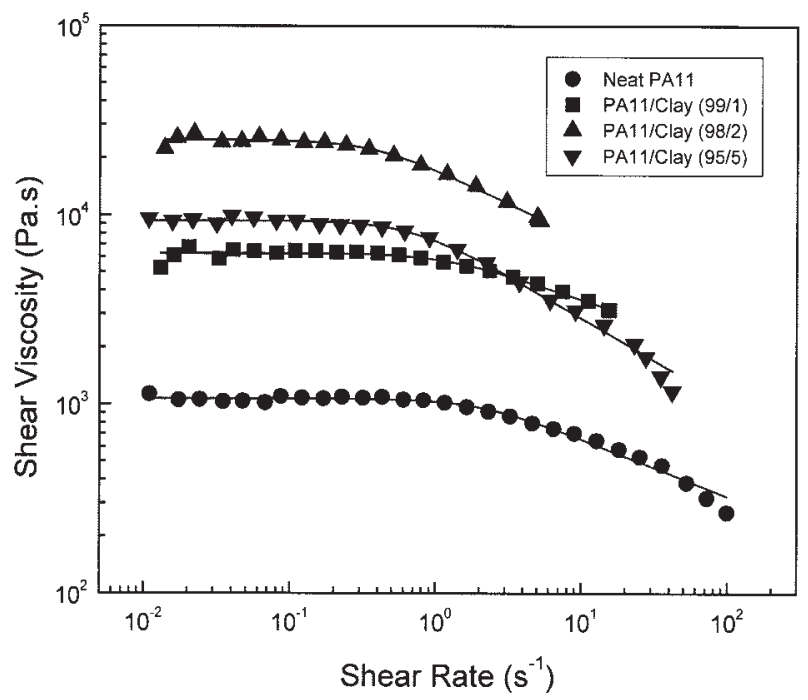

Figure 6 Steady shear viscosity versus shear rate for neat PA11 and its clay nanocomposites at $210^{\circ} \mathrm{C}$. Symbols are the experimental data, and solid lines are the best fit with eq. (1).

and its nanocomposites, as shown in Figure 6 by using the solid lines. It is seen that the experimental data fit quite well with the following equation:

$$
\eta=\frac{\eta_{0}}{\left[1+\left(\dot{\gamma} t_{1}\right)^{2}\right]^{(1-n) / 2}}
$$

Here, $\eta_{o}$ is the zero shear rate viscosity, $t_{1}$ is the characteristic time, $\dot{\gamma}$ is shear rate, and $n$ is a dimensionless parameter. Then, the slope of $\eta$ versus $\dot{\gamma}$ on a $\log$-log plot in the power-law region is $(n-1)$, where $n$ is called non-Newtonian index. The lower the value of $n$, the more deviation from a Newtonian fluid. For $n$ $=1$ or $\dot{\gamma} t_{1} \rightarrow 0$, eq. (1) reduces to the Newtonian fluid behavior, and this model predicts shear-thinning behavior for $n<1$. The calculated values of $\eta_{o}, t_{1}$, and $n$ are presented in Table I. One can see that $\eta_{o}$ increases drastically with clay loading, whereas $n$ decreases for higher clay contents, implying occurrence of distinct shear thinning behavior for PA11 nanocomposites due to addition of clay.

Additionally, there is a sharp transition from the Newtonian plateau region to the power-law region for each flow curve, as observed in poly(ethylene oxide)/ clay nanocomposites. ${ }^{31}$ Then, the critical shear rate $\left(\dot{\gamma}_{c}\right)$ is defined as the onset point of shear-thinning transition and is approximately equal to the inverse of $t_{1}$ (or the longest relaxation time). From Table I, $\dot{\gamma}_{c}$ is estimated to be $2.08,1.16,0.40$, and $0.72 \mathrm{~s}^{-1}$ for neat PA11 and the nanocomposites with 1,2, and 5 wt \% clay, respectively. Hence, the addition of clay renders the transition from the Newtonian plateau region to shear-thinning region occurring at lower critical shear rate with increasing the clay concentration. This might suggest that the clay platelets are ease of orientation when being subject to external stress.

\section{Cox-Merz rule}

The relation between the complex viscosity $\left(\eta^{*}(\omega)\right)$ and the steady shear viscosity $(\eta(\gamma))$ is usually described using the Cox-Merz rule. ${ }^{32}$ That is, within experimental error, the complex viscosity is equal to the steady shear viscosity over a range of frequencies and shear rates:

$$
\left|\eta^{*}(\omega)\right|=|\eta(\dot{\gamma})|_{\dot{\gamma}-\omega}
$$

The Cox-Merz relation (here named by type-I) is helpful for studying polymer melts, since it can provide steady shear viscosity data outside the normal measurement range. For example, the onset of secondary flow and edge fracture often prevents measuring melt viscosity at shear rates above $1.0 \mathrm{~s}^{-1}$. However, complex viscosity measurements can be made on the polymer melts at frequencies as high as $500 \mathrm{rad} / \mathrm{s}$. Therefore, application of the Cox-Merz relation to these complex viscosity data provides the possibility of studying steady shear viscosity data at a shear rate two and half decades higher than otherwise achievable. The limitation of steady-state data at high shear rates is obvious for PA11/clay nanocomposites as shown in Figure 6. The highest shear rate achieved for the sample with $2 \mathrm{wt} \%$ clay is only $6.0 \mathrm{~s}^{-1}$, which is much lower than that of neat PA11 $\left(100 \mathrm{~s}^{-1}\right)$. Thus, Cox-Merz rule provides an alternative way to obtain the steady shear viscosity of PA11 nanocomposites at high shear rate.

Figure 7 compares steady shear and dynamic viscosity data for neat PA11 and the nanocomposite sam-

TABLE I

Parameters Obtained by the Carreau Model from Eq. (1) for PA11 and Its Nanocomposites as a Function of Clay Concentration

\begin{tabular}{lcccc}
\hline \multicolumn{1}{c}{ Samples } & $\eta_{o}($ Pa s $) \times 10^{-2}$ & $t_{1}(\mathrm{~s})$ & $n$ & $\dot{\gamma}_{c}\left(\mathrm{~s}^{-1}\right)$ \\
\hline Neat PA11 & 10.7 & 0.48 & 0.69 & 2.08 \\
PA11/Clay (99/1) & 62.7 & 0.86 & 0.74 & 1.16 \\
PA11/Clay (98/2) & 248.1 & 2.51 & 0.63 & 0.40 \\
PA11/Clay (95/5) & 93.1 & 1.39 & 0.55 & 0.72 \\
\hline
\end{tabular}


ples. One can see that neat PA11 does not conform to the Cox-Merz relation (eq. (2)) but to the relation of $\eta(\gamma) \chi \eta^{*}(\omega) \chi$; while the nanocomposites only exhibit small deviation from the Cox-Merz rule, especially for the sample with $1 \mathrm{wt} \%$ clay. This indicates that the addition of clay increases the dynamic viscosities of PA11. This also reflects the thixotropic characteristic of the nanocomposites under large strain deformation, probably indicating the collapse of certain structures (e.g., networks or aggregates). For small strain oscillation deformation, however, such structures maintain their stability and higher complex viscosities are obtained. The rotation of clay platelets upon shearing could be a factor for the decrease of shear viscosity.

Another expression form of the Cox-Merz rule (named by type-II) correlates the first derivative of shear stress $(\tau)$ with respect to strain, that is, the socalled "consistency," with the imaginary part of the dynamic viscosity with the following expression ${ }^{32}$ :

$$
\frac{d \tau(\dot{\gamma})}{d \dot{\gamma}}=\frac{G^{\prime \prime}(\omega)}{\omega}
$$

Here $\tau$ is shear stress and $\omega$ is angular frequency. The comparison of the two quantities (i.e., the consistency and the imaginary part of the complex viscosity) is shown in Figure 8. One can see distinct deviation between the two quantities for neat PA11 and its nanocomposites. The results indicate that the nanocomposites follow type-I Cox-Merz rule but do not fit the type-II. Although the exact reasons why PA11 nanocomposites fit well with the type-I Cox-Merz rule are not clear currently, it is believed that morphologies of the nanoclay platelets in the matrix as well as the interaction of polymer chains with the clay nanofiller might play an important role. Similar findings were

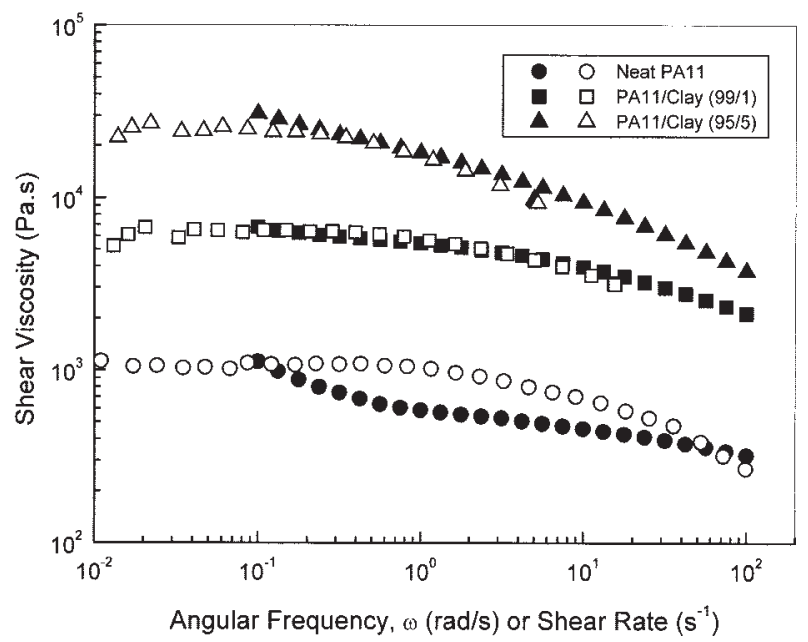

Figure 7 Dynamic complex viscosities (solid symbols) and steady viscosities (open symbols) at $210^{\circ} \mathrm{C}$ for neat PA11 and its nanocomposites.

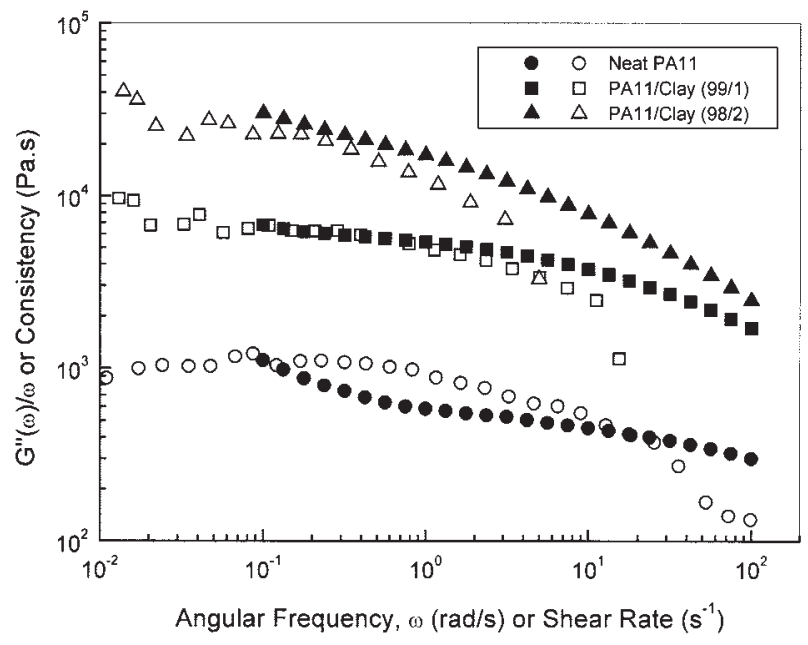

Figure 8 Consistency (open symbols) and imaginary part of the complex viscosity (solid symbols) for neat PA11 and its nanocomposites at $210^{\circ} \mathrm{C}$.

reported for linear and randomly branched polystyrenes (LPS and RBPS). ${ }^{33}$ In this report, type-II rule is better followed for RBPS than for LPS, and inverse result is found for type-I. It is suggested that the existence of branching in RBPS may be responsible for the failure of type-I rule.

\section{CONCLUSIONS}

Morphology and melt rheological properties of nylon 11 and its clay nanocomposites have been studied in this work. It has been found that the dispersion morphology of clay particles in the matrix has remarkable influence on the melt rheological properties of nylon 11 and the nanocomposites. The ordered nanoclay stacks are responsible for the abnormal dependence of both linear and nonlinear viscoelastic responses at high clay loading (e.g., $5 \mathrm{wt} \%$ ). Compared with neat PA11, though all the nanocomposites exhibit much higher $G^{\prime}, G^{\prime \prime}$, and shear viscosities, the plateaus in $G^{\prime}$ and $G^{\prime \prime}$ at low frequencies are not observed. In addition, the nanocomposites generally obey the type-I Cox-Merz rule [eq. (2)], which is useful to estimate shear viscosities at higher shear rates from the dynamic data. However, the type-II Cox-Merz rule [eq. (3)] is not applicable to all the samples studied here.

\section{References}

1. Bottino, F. A.; Fabbri, E.; Fragala, I. L.; Malandrino, G.; Orestano, A.; Pilati, F.; Pollicino, A. Macromol Rapid Commun 2003, 24, 1079.

2. Yu, Y. H.; Lin, C. Y.; Yeh, J. M. J Appl Polym Sci 2004, 91, 1904.

3. Aranda, P.; Mosqueda, Y.; Perez-Cappe, E.; Ruiz-Hitzky, E. J Polym Sci Part B: Polym Phys 2003, 41, 3249.

4. Tang, Y.; Hu, Y.; Wang, S. F.; Gui, Z.; Chen, Z. Y.; Fan, W. C. Polym Adv Technol 2003, 14, 733. 
5. Kuo, S. W.; Huang, W. J.; Huang, S. B.; Kao, H. C.; Chang, F. C. Polymer 2003, 44, 7709.

6. Ou, C. F. J Polym Sci Part B: Polym Phys 2003, 41, 2902.

7. Takeichi, T.; Guo, Y. J Appl Polym Sci 2003, 90, 4075.

8. Zhang, W. A.; Liang, Y.; Luo, W.; Fang, Y. E. J Polym Sci Part A: Polym Chem 2003, 41, 3218.

9. Xu, M. Z.; Choi, Y. S.; Kim, Y. K.; Wang, K. H.; Chung, I. J. Polymer 2003, 44, 6387.

10. Jeon, H. S.; Rameshwaram, J. K.; Kim, G.; Weinkauf, D. H. Polymer 2003, 44, 5749.

11. Zheng, X. X.; Wilkie, C. A. Polym Degrad Stab 2003, 81, 539.

12. Kato, M.; Okamoto, H.; Hasegawa, N.; Tsukigase, A.; Usuki, A. Polym Eng Sci 2003, 43, 1312.

13. Khayankarn, O.; Magaraphan, R.; Schwank, J. W. J Appl Polym Sci 2003, 89, 2875.

14. Kojima, Y.; Usuki, A.; Kawasumi, M.; Okada, A.; Kurauchi, T.; Kamigaito, O. J Polym Sci Part A: Polym Chem 1993, 31, 983.

15. Usuki, A.; Kawasumi, M.; Kojima, Y.; Okada, A.; Kurauchi, T.; Kamigaito, O. J Mater Res 1993, 8, 1174.

16. Usuki, A.; Kojima, Y.; Kawasumi, M.; Okada, A.; Fukushima, Y.; Kurauchi, T.; Kamigaito, O. J Mater Res 1993, 8, 1179.

17. Krishnamoorti, R.; Yurekli, K. Curr Opin Colloid Interf Sci 2001, 6, 464 .

18. Cho, J. W.; Paul, D. R. Polymer 2001, 42, 1083.

19. Pinnavaia, T. J.; Beal, G. W. Polymer-Clay Nanocomposites; Wiley: New York, 2000.
20. Liu, T. X.; Lim, K. P.; Tjiu, W. C.; Pramoda, K. P.; Chen, Z. K. Polymer 2003, 44, 3529.

21. Li, Y. J.; Kaito, A. Polymer 2003, 44, 8167.

22. Liu, S. Y.; Yu, Y. N.; Cui, Y.; Zhang, H. F.; Mo, Z. S. J Appl Polym Sci 1998, 70, 2371.

23. Ferry, J. D. Viscoelastic Properties of Polymers, 3rd ed.; Wiley: New York, 1980

24. Galgali, G.; Ramesh, C.; Lele, A. Macromolecules 2001, 34, 852.

25. Luengos, G.; Schmitt, F.; Hill, R.; Israelachvili, J. Macromolecules 1997, 30, 2482.

26. Khare, R.; Pablo, J.; Yethiraj, A. M. Macromolecules 1996, 29, 7910.

27. Krishnamoorti, R.; Giannelis, E. P. Macromolecules 1997, 30, 4097.

28. Solomon, M. J.; Almusallam, A. S.; Seefeldt, K. F.; Somwangthanaroj, A.; Varadan, P. Macromolecules 2001, 34, 1864.

29. Lim, Y. T.; Park, O. O. Macromol Rapid Commun 2000, 21, 231.

30. Carreau, P. J.; De Kee, D. C. R.; Chhabra, R. P. Rheology of Polymeric Systems: Principles and Applications; Hanser: Munich, 1997.

31. Hyun, Y. H.; Lim, S. T, Choi, H. J.; Jhon, M. S. Macromolecules 2001, 34, 8084 .

32. Wu, Q.; Wu, J. Polymer Rheology; Higher Education Publisher: Beijing, 2002.

33. Ferri, D.; Lomellini, P. J Rheology 1999, 43, 1355. 